\title{
Cultivating inclusive instructional and research environments in ecology and evolutionary science
}

\author{
Nathan Emery ${ }^{1}$, Ellen Bledsoe ${ }^{2}$, and Andrew Hasley ${ }^{3}$ \\ ${ }^{1}$ Michigan State University \\ ${ }^{2}$ University of Florida \\ ${ }^{3}$ Affiliation not available
}

June 17, 2020

\begin{abstract}
As science and student populations continue to diversify, it is important for ecologists, evolutionary scientists, and educators to foster inclusive environments in their research and teaching. Academics are often poorly trained in diversity, equity, and inclusion best practices and may not know where to start to make scientific environments more welcoming and inclusive. We propose that by approaching research and teaching with empathy, flexibility, and a growth mindset, scientists can be more supportive and inclusive of their colleagues and students. This paper provides guidance, explores strategies, and directs scientists to resources to better cultivate an inclusive environment in three common settings: the classroom, the research lab, and the field. As ecologists and evolutionary scientists, we have an opportunity to adapt our teaching and research practices in order to foster an inclusive educational ecosystem for students and colleagues alike.
\end{abstract}

\section{Hosted file}

Inclusivity_MS.pdf available at https://authorea.com/users/334254/articles/460279cultivating-inclusive-instructional-and-research-environments-in-ecology-and-

evolutionary-science 


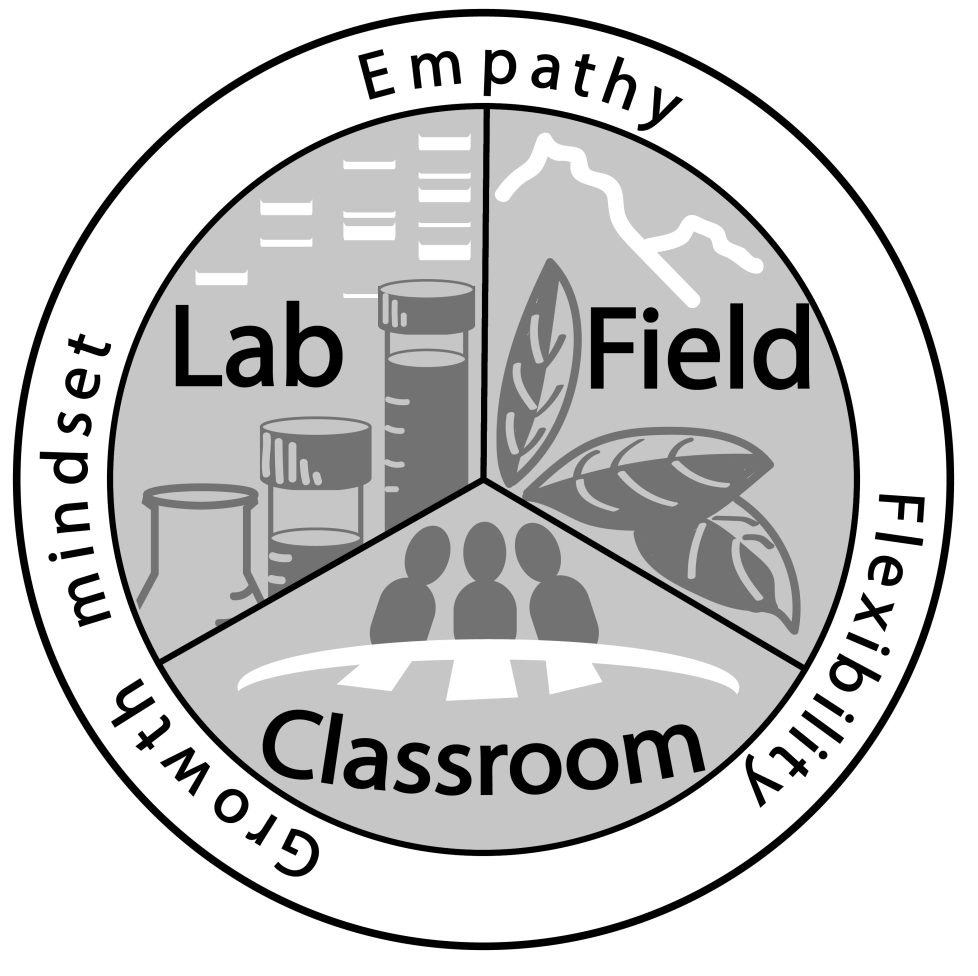

